\title{
Glyceraldehyde-3-phosphate dehydrogenase as a surface associated antigen on human breast cancer cell lines MACL-1 and MGSO-3
}

\author{
C.R. CORREA, C.M. BERTOLLO, C.S.ZOUAIN and A.M.GOES
}

\author{
Departamento de Bioquímica e Imunologia, Instituto de Ciências Biológicas, Universidade Federal \\ de Minas Gerais (UFMG), Caixa Postal 486, CEP 31.270-901, Belo Horizonte, MG, Brazil
}

Received January 22, 2010; Accepted March 29, 2010

DOI: $10.3892 /$ or_00000907

\begin{abstract}
Breast cancer is a major health burden, responsible for $>10 \%$ of all cases of cancer worldwide. Advances in breast cancer diagnosis and treatment have contributed to an improved rate of survival, although mortality rates remains significantly high. The establishment of breast cancer cell lines is an important model for understanding biological processes involved in this disease and for identifying potential therapeutic targets. The novel human breast cancer cell lines, MACL-1 and MGSO-3, were used in this study to identify possible surface antigens by antibodies directed against two commercial breast cancer cell lines MCF-7 and MDA-MB-231. We purified a $37 \mathrm{kDa}$ antigen by affinity chromatography from MDA-MB231, and its N-terminal amino acid sequence was homologous to glyceraldehyde-3-phosphate dehydrogenase (GAPDH). Therefore, immunohistochemical experiments, using specific monoclonal antibodies, evidenced a co-localization of GAPDH and $\mathrm{Na}^{+} / \mathrm{K}^{+}$-ATPase on the surface of commercially available and recently established breast cancer cell lines. It is of note that $\mathrm{Na}^{+} / \mathrm{K}^{+}$-ATPase was used as a plasma membrane marker. This finding opens new perspectives for breast cancer diagnosis and treatment since GAPDH could be used as a biomarker or as a potential therapeutic target in breast cancer.
\end{abstract}

\section{Introduction}

Cancer is a public health problem worldwide. Among the various types of cancer, breast cancer is the most common in women, in both high and low-resource settings, and is responsible for over one million of the estimated 10 million neoplasms diagnosed in both sexes worldwide each year (1). It is also the primary cause of death among women globally,

Correspondence to: Dr A.M. Goes, Departamento de Bioquímica e Imunologia, Instituto de Ciências Biológicas, UFMG, Caixa Postal 486, CEP 31.270-901, Belo Horizonte, MG, Brazil E-mail:goes@icb.ufmg.br

Key words: antigen, breast cancer, GAPDH, cell line responsible for $\sim 375,000$ deaths in the year 2000 (1). Although the 5-year survival rate has greatly increased as a result of advances in detection and treatment, many breast cancer patients still die from metastatic disease. Therefore, more effective methods of prevention and treatment are greatly needed.

Cell cultures, established directly from patients, are an important model for examining and manipulating the potentially relevant molecules and cellular processes underlying malignant breast disease. However, selective culture of neoplastic cells and successful establishment of new cell lines have rarely been reported from primary breast carcinomas $(2,3)$.

The discovery of T-cell recognition and subsequent lysis of human tumors led to the identification of specific oncoproteins or mutated oncogenes (e.g., MUC-1, HER-2, CEA, and p53) (4-7). Many of these tumor antigens are found on normal tissues, but in cases of oncogenesis, are recognized by the immune system due to their overexpression. Some proteins are tumor-specific, but others, such as the universal tumor Ag hTERT, are broadly expressed by most tumor cells $(8,9)$.

In the present study, we describe a potential therapeutic target antigen on breast cancer cell lines, established from primary breast carcinoma by Correa et al (9). Using antibodies directed against the commercial cell lines MCF-7 and MDAMB-231, we were able to identify antigens that are commonly expressed by both these existing cell lines and our new cell lines. After sequencing, we found an antigen to be homologous with glyceraldehydes-3-phosphate dehydrogenase (GAPDH). This enzyme is a key regulator of glycolysis, but several lines of evidence indicate that it is involved in various biological processes such as endocytosis, control of gene expression, DNA replication and repair, as well as neuronal apoptosis (10). Moreover, it has been demonstrated that GAPDH expression is substantially increased in human cancers of various origins, such as the lung (11), pancreas (12), and cervix (13).

Over the past years several laboratories, including ours $(9,14)$, have established and characterized cell lines derived from tumors. However, the majority of these cell lines were established from patient ascites or metastasis and only few were derived from primary solid tumors. In this study, we describe the antigen characterization on two new primary 
breast cancer cell lines that were established in our laboratory from solid tumors (9).

\section{Materials and methods}

Cell lines. Two primary breast cancer cell lines were used: MACL-1 and MGSO-3. These cell lines were established from fragments of breast tumors in our laboratory by Correa et al (9). The human breast carcinoma MDA-MB-231 cell line was purchased from the American Type Cell Culture (ATCC). All cell lines were cultured in Dulbecco modified Eagle's medium (DMEM, Gibco, USA) with $10 \%$ fetal calf serum, $200 \mathrm{mM}$ glutamine, $100 \mu \mathrm{g} / \mathrm{ml}$ streptomycin, and $100 \mathrm{U} / \mathrm{ml}$ penicillin. All cultures were kept in a humidified incubator with $5 \% \mathrm{CO}_{2}$ at $37^{\circ} \mathrm{C}$.

Morphological examination and cellular viability. All tumorlike epithelial cells grown in the flasks were examined directly with an inverted microscope, and phase-contrast microphotographs were taken periodically. Cell proliferation was measured by MTT assay, based on the reduction of tetrazolium salt to formazan crystals by living cells. Briefly, cells were seeded into 96-well plates and, on the day of harvest, $100 \mu 1$ of spent medium was replaced with an equal volume of fresh medium containing $10 \%$ MTT (5 mg/ml stock). Plates were incubated at $37^{\circ} \mathrm{C}$ for $2 \mathrm{~h}$, followed by the addition of $70 \mu \mathrm{l}$ of $10 \% \mathrm{SDS} /$ $\mathrm{HCl}$ to each well. After overnight incubation, cellular viability was determined by measuring the absorbance of the converted dye at a wavelength of $595 \mathrm{~nm}$

Alkaline phosphatase activity. The alkaline phosphatase production was evaluated by BCIP-NBT assay. This assay is based on a chromogenic reaction initiated by the cleavage of the phosphate group of BCIP by alkaline phosphatase present in the cells. This reaction produces a proton that reduces NBT to an insoluble purple precipitate. Briefly, the supernatant of each well was removed, and the cell layer was rinsed twice with PBS. Then, $200 \mu 1$ of BCIP-NBT solution, prepared to the manufacturer's protocol, was added to each well. After $24 \mathrm{~h}$ of incubation, the cells were observed by optical microscopy, and the insoluble purple precipitates were solubilized with $210 \mu \mathrm{l}$ of SDS $10 \% \mathrm{HCl}$ and incubated overnight. The optical density measurement was done at $595 \mathrm{~nm}$.

Antibody production against MCF-7 and MDA-MB-231 cells. Two adult New Zealand rabbits were immunized 3 times with $10^{6}$ to $10^{7} \mathrm{MCF}-7$ and MDA-MB-231 cells fixed with $4 \%$ paraformaldehyde, $100 \mu \mathrm{g}$ of Propionium acnes (Ataulpho de Paiva Foundation, Brazil), and $6 \mathrm{mg}$ of Alumen. Blood was collected from the auricular vein 7 to 15 days after each immunization. Serum was collected from the blood by centrifugation at $10,000 \mathrm{x} \mathrm{g}$ for $10 \mathrm{~min}$, and stored at $-20^{\circ} \mathrm{C}$. Pre-immune sera were used as normal serum control.

Enzyme-linked immunosorbent assay (ELISA). The rabbit antiMCF-7 and MDA-MB-231 sera were evaluated by ELISA. Individual wells of polystyrene 96-well flat bottom plates (Nunc) were coated with $1 \mu \mathrm{g} / \mathrm{ml}$ of MCF-7 or MDA-MB231 antigen preparations/well, diluted in coating buffer $(0.05 \mathrm{M}$ carbonate buffer, $\mathrm{pH} 9.6)$, and incubated overnight at $4^{\circ} \mathrm{C}$.
The unsaturated protein binding sites were blocked with $300 \mu \mathrm{l} /$ well of $1.6 \%$ casein/PBS and $0.05 \%$ Tween-20 for $1 \mathrm{~h}$ at room temperature. The primary anti-tumor cell anti-sera were added in serial dilutions in triplicates, and the wells were incubated for $1 \mathrm{~h}$ at $37^{\circ} \mathrm{C}$. After thorough washing, the wells were incubated with goat anti-rabbit IgG serum conjugated with peroxidase (Sigma, USA), diluted 1/5000 in blocking buffer for $1 \mathrm{~h}$ at room temperature. The enzyme activity was revealed by adding the substrate solution containing $0.5 \mathrm{mg} / \mathrm{ml}$ orthophenylenediamine in citrate buffer, $\mathrm{pH} 5.0$ and $0.5 \mu \mathrm{l} / \mathrm{ml}$ $\mathrm{H}_{2} \mathrm{O}_{2}$. The enzyme reaction was stopped by addition of $50 \mu \mathrm{l} /$ well of $\mathrm{H}_{2} \mathrm{SO}_{4}$, and the color reaction was read at $492 \mathrm{~nm}$ in a Micro ELISA reader.

Flow cytometric analysis. Breast cancer cell lines were released from cultures by trypsinization. Approximately $1 \times 10^{6}$ cells/ well were incubated with sera generated by rabbit response to MCF-7 and MDA-MB-231 cell lines exposure, diluted 1/50 for $30 \mathrm{~min}$ at $4^{\circ} \mathrm{C}$. After washing with PBS, the cells were incubated with Alexa 488 anti-rabbit IgG (Sigma) for 30 min at $4^{\circ} \mathrm{C}$ and then washed with PBS. The cells were fixed with $200 \mu \mathrm{l}$ of $4 \%$ paraformaldehyde and acquired using a fluorescence-activated cell sorter (FACSCalibur; Becton Dickinson, USA). The data was analyzed with CellQuest Software. Event numbers were 30,000 .

Antibodies and antigens affinity purification. Antibodies were purified by affinity chromatography on nitrocellulose (NC) membranes. NC membranes were coated with cellular extracts from MCF-7 and MDA-MB-231 cell lines, diluted in $5 \mathrm{ml}$ of PBS, for $1 \mathrm{~h}$ at room temperature. The membrane was dried and then incubated with anti-sera (1/50 diluted in casein/PBS) for $1 \mathrm{~h}$ at room temperature. After washing, membranes were treated with $0.1 \mathrm{M}$ glicin- $\mathrm{HCl}, \mathrm{pH} 2.5$ buffer, for $5 \mathrm{~min}$ at room temperature. Supernatants were collected, and $\mathrm{pH}$ was neutralized with Ultra-Pure Tris (Invitrogen, USA). Purified antibodies were lyophilized and dialyzed in $50 \mathrm{mM}$ PBS. These antibodies were coated to NC membranes to allow the purification of antigens from $\mathrm{MCF}-7$ and MDAMB-231 cell lines.

Western blot analysis. Cell lysates were prepared by treating cells with lysis buffer (2\% NP40, Calbiochem, USA, and $1 \%$ protein kinase inhibitor cocktail, Sigma). Lysates were put on ice for $15 \mathrm{~min}$ and centrifuged at $10,000 \mathrm{x}$ g for $30 \mathrm{~min}$. The protein concentration of the supernatant was measured by the Bradford method (15). Protein (50 $\mu \mathrm{g})$ was resolved on a $12 \%$ SDS-polyacrylamide gel. The proteins were transferred to a nitrocellulose membrane, and the membrane was then blocked in $1.6 \%$ casein/PBS at room temperature for $1 \mathrm{~h}$. Membranes were probed with rabbit primary anti-MCF-7 or anti-MDAMB-231 antibody (1/400) and then probed with a corresponding horseradish peroxidase-conjugated secondary antibody in PBS. The blots were visualized using $6 \mathrm{mg}$ of DAB (3,3'-diaminobenzidine, Sigma) and $100 \mu 1$ of $5.5 \%$ nickel chloride diluted in $10 \mathrm{ml}$ of $0.15 \mathrm{M}$ PBS; $10 \mu 1$ of $32 \%$ $\mathrm{H}_{2} \mathrm{O}_{2}$ was added just before development.

Indirect immunofluorescence assay (IFA) and confocal microscopy. Cells grown on chamber slides (LabTakII, Nunc) were 

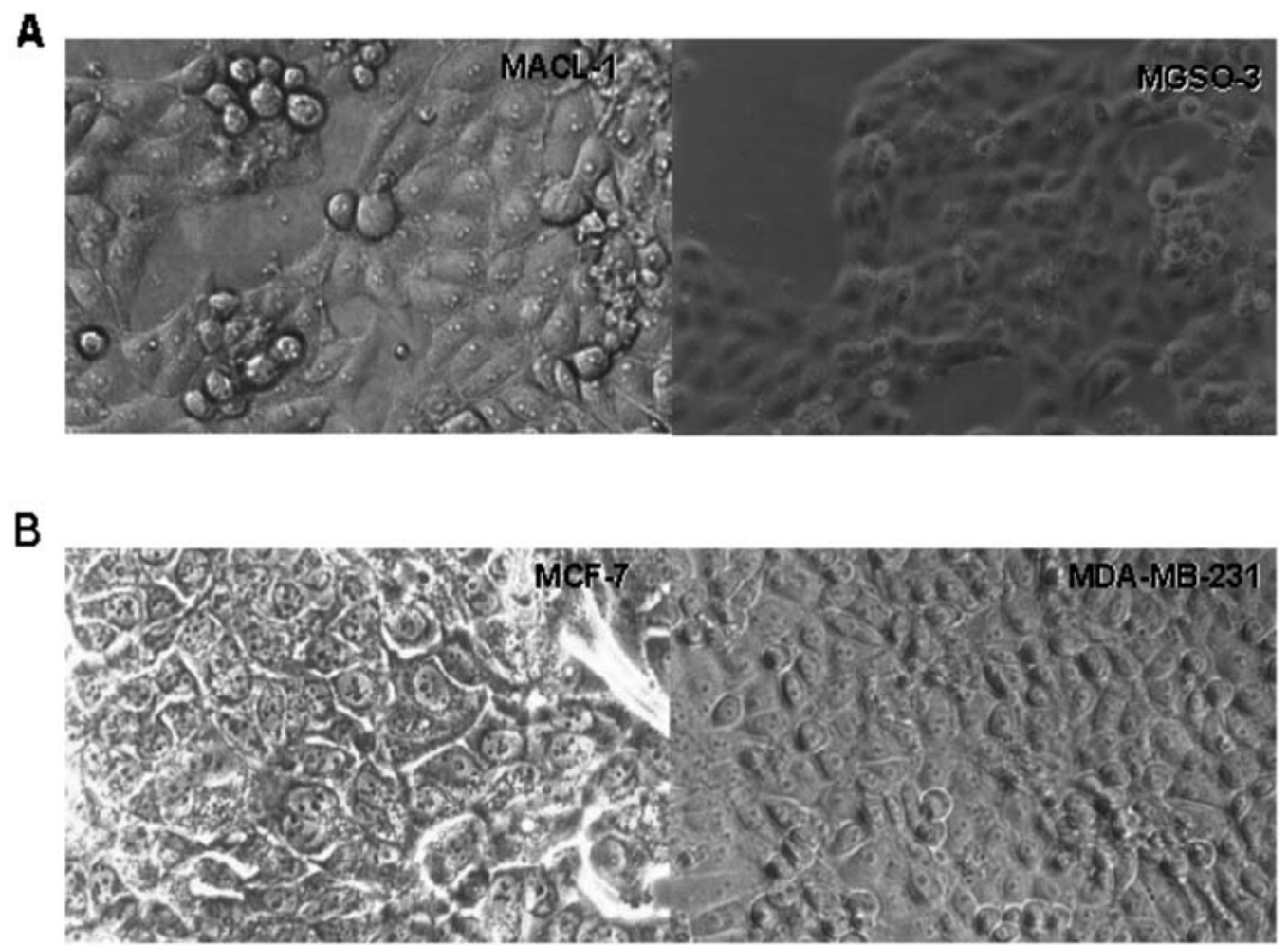

Figure 1. Cellular morphology of breast cancer cell lines in vitro. (A) Primary cell lines MACL-1 (magnification, x20) and MGSO-3 (magnification, x15). (B) Commercial breast cancer cell lines MCF-7 (magnification, x20) and MDA-MB-231 (magnification, x15). Optical microscopy.

washed twice with PBS, fixed with $4 \%$ paraformaldehyde for $30 \mathrm{~min}$, washed again with PBS, and then incubated for $1 \mathrm{~h}$ at room temperature with $1.6 \%$ casein/PBS. Cells were then incubated consecutively with monoclonal antibodies against GAPDH (Santa Cruz, USA), diluted $1 / 50$, and anti- $\mathrm{Na}^{+} / \mathrm{K}^{+}$ ATPase (Upstate, USA), diluted 1/200. After several washes, Alexa 488-conjugated goat anti-mouse antibodies (Molecular Probes, USA) in a 1/500 dilution was added for $1 \mathrm{~h}$ at room temperature. Images were analyzed using a confocal laserscanning microscope (CLSM Bio-Rad 1024). Data were processed with Adobe Photoshop 5.5 software.

$N$-terminal amino acid sequencing and homology analyses. Affinity purified antigens were transferred from the SDSpolyacrylamide gel to a PVDF membrane (Bio-Rad, USA); the membrane was stained with Ponceau. The more reactive bands were excised, and the N-terminal sequence was determined using PPSQ-21A (Shimadzu). Amino acid sequence was analyzed by the protein-protein-BLAST data bank from NCBI (www.ncbi.nlm.nih.gov/BLAST) to search for homologies.

Statistical analysis. The statistical significance of differences between experimental groups was calculated using the ANOVA and Bonferroni's post-test. $\mathrm{p}<0.05$ was considered significant.

\section{Results}

Morphology and culture characteristics. The novel human breast cancer cell lines, MACL-1 and MGSO-3, established from fragments of breast tumors by Correa et al (9) in our laboratory, grew as an adherent monolayer with characteristic epithelial morphologic features (Fig. 1). The cells maintained consistent morphology from the primary culture to the following passages. After thawing, the cryo-preserved cells could be propagated in culture without noticeable change in growth and morphology.

The cell viabilities and proliferative capacities of primary tumor cultures (MACL-1, MGSO-3) and immortal cell lines (MCF-7, MDA-MB-231) were compared with the control human fibroblast cell line (FS4). Among tumors cells, MCF-7 showed major cell viability, more than two-fold of the control. In the other cell lines, cell viability was observed in $70 \%$ of MDAMB-231, $80 \%$ of MACL-1, and $50 \%$ of MGSO-3 (Fig. 2).

The production of alkaline phosphatase was used as a biomarker for cancer detection, since this enzyme is upregulated in some tumor cells. Therefore, the activity of alkaline phosphatase was measured in the primary tumor cultures (MACL-1, MGSO-3), in immortal cell lines (MCF-7, MDA-MB-231), and the control human fibroblast cell line (FS4), that express this enzyme at a basal level. Among the tumors cells, MCF-7 showed the most alkaline phosphatase activity, $>75 \%$ of the control. In the other cell lines, alkaline phosphatase activity was observed the similar increasing pattern, $50 \%$ of MDA-MB-231 and MACL-1 and $>25 \%$ in MGSO-3 (Fig. 3).

Identification of common antigens in breast cancer cell lines. The identification of common antigens in breast cancer cell lines was done via Western blot analysis of cell lysates of 


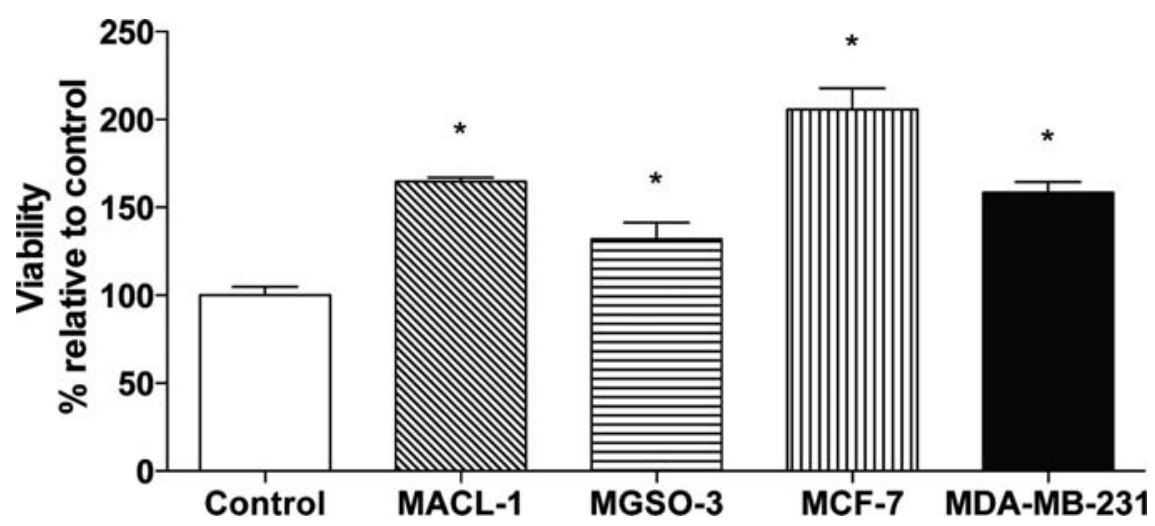

Figure 2. Viability of breast cancer cell lines measured by MTT assay. Cells at $1 \times 10^{5}$ densities were seeded in 96 -well plates. Cell viability was evaluated $24 \mathrm{~h}$ later. Viability of cancer cell lines was increased compared to fibroblasts, used as controls. Data represent mean \pm SEM of triplicates from three independent experiments. ${ }^{*} \mathrm{p}<0.05$.

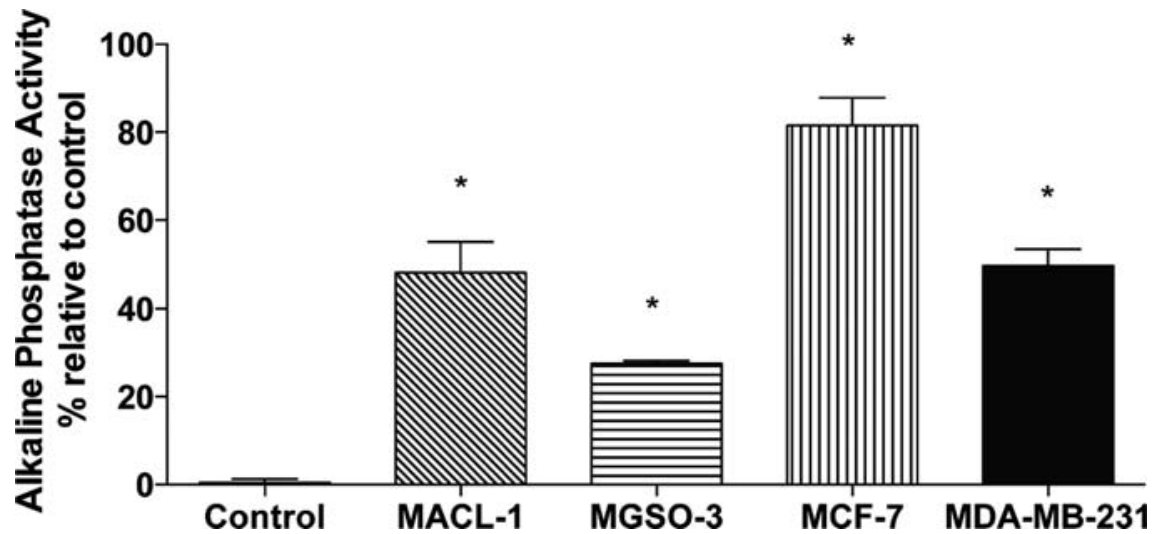

Figure 3. Phosphatase alkaline production by breast cancer cell lines. Cells at $1 \times 10^{5}$ densities were seeded in 96 -well plates. After $24 \mathrm{~h}$ of incubation, alkaline phosphatase production was evaluated by NBT/BCIP assay. Data represent mean \pm SEM of three independent experiments. ${ }^{*} \mathrm{p}<0.05$.

breast cancer cell lines (MACL-1, MGSO-3, MCF-7, MDAMB-231) and some non-breast cancer human cells (PBMC, HEK, HELA). These results were further validated using rabbit antibody against MCF-7 or MDA-MB-231 by flow cytometry. In Western blot experiments, the presence of at least four common antigens was observed, with different molecular weights ranging from 28 to $125 \mathrm{kDa}$, among breast cancer cell lines. Conversely, these antigens could not be observed in the lysate of non-breast cancer human cell lines (Fig. 4).

Identification of surface antigens in breast cancer cell lines. The detection of surface antigens in breast cancer cell lines was done by an immunofluorescence assay, using rabbit antiMDA-MB-231 and anti-MCF-7 antibodies. According to our results, the presence of surface antigens can be observed by fluorescence in MDA-MB-231, MCF-7, MACL-1, and MGSO-3 cell lines. However, control cells did not display any surface fluorescence (Fig. 5). The same results were obtained across flow cytometry analysis, with a significant percentage of MACL-1, MGSO-3, MCF-7, and MDA-MB-231 cells staining positively for anti-MCF-7 (Fig. 6) and MDA-MB231 (Fig. 7) antibodies.

Evidence of GAPDH protein on the surface of breast cancer cell lines. After the purification of the antigens from membrane cellular extracts of MDA-MB-231 by affinity chromatography, the N-terminal sequence was determined for four purified antigens with different molecular weights. The amino acid sequences of the proteins of 95,81 and $28 \mathrm{kDa}$ did not present significant homology with any protein sequences deposited in databases. However, the amino acid sequence of the protein of $\sim 37 \mathrm{kDa}$ showed a $100 \%$ of homology with the human protein GAPDH (Table I).

In order to investigate if the GAPDH protein should be present at the plasma membrane of breast cancer cell lines, immunofluorescence using specific monoclonal antibodies was used to co-localize GAPDH and $\mathrm{Na}^{+} / \mathrm{K}^{+}$-ATPase, a known component of the cellular membrane. The results presented in Fig. 8 showed that the monoclonal antibodies used recognized GAPDH and $\mathrm{Na}^{+} / \mathrm{K}^{+}$-ATPase localized on the cell surface of MACL-1, MGSO-3, MCF-7 and MDAMB-231.

\section{Discussion}

In the present study, the characterization and identification of surface antigens in the new human breast cancer cell lines established by Correa et al (9) represent an important model to understand the biological processes involved in cancer development and for the study of new biomarkers. However, 
Table I. MDA-MB-231 breast cancer cell line $37 \mathrm{kDa}$ antigen $\mathrm{N}$-terminal amino acid sequence identification according to protein sequences deposited in non-redundant databases.

\begin{tabular}{|c|c|c|c|c|}
\hline Description & Accession & E-value & Ident (Sim) \% & Score (bits) \\
\hline Glyceraldehyde-3-phosphate dehydrogenase (Homo sapiens) & CAA25833 & 0.043 & $100(100)$ & 33.3 \\
\hline
\end{tabular}

Ident (Sim), identity and similarity. N-terminal amino acid sequence VKVGVNGFGR of MD-AMB-231 breast cancer cell line. This peptide was compared to protein sequences in non-redundant databases, using the Basic Local Alignment Search Tool program, BLASTp.

A

B
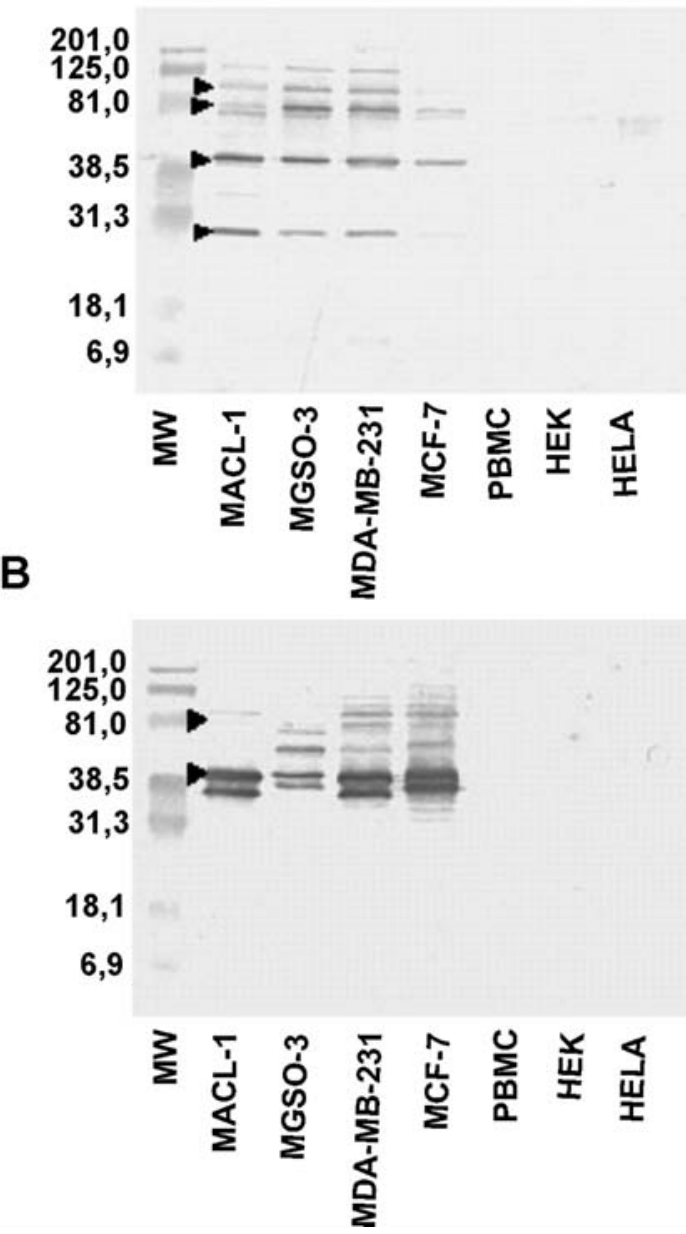

Figure 4. Identification of antigens commonly expressed in primary breast cancer cell lines and commercial cell lines by Western blotting. (A) After SDS-PAGE electrophoresis, proteins were transferred to a nitrocellulose membrane and probed with anti-MDA-MB-231 rabbit serum (1:400). (B) After SDS-PAGE electrophoresis, proteins were transferred to a nitrocellulose membrane and probed with anti-MCF-7 rabbit serum (1:400). Data represent four different experiments.

neoplastic selective cell culture and the establishment of new cell lines are rarely reported for breast cancer $(2,3)$. The most commonly used cell lines are not derived from primary tumors but from metastasis, as is the case for both MCF-7 and MDAMB-231 cell lines, derived from pleural perfusion (16). Therefore, MCF-7 and MDA-MB-231 cell lines may not represent the real nature of primary tumor cells. Increasing the number of established primary cell lines might raise the chances of developing more appropriate models for the study of breast cancer.

Since Valenti et al (17) demonstrated that fibroblasts from normal breast tissue decay irreversibly after 12 passages; the MACL-1 and MGSO-3 cell lines used in our work were subjected to 20 consecutive passages to guarantee the elimination of normal cells. The cell lines were adherent and confluent in $\sim 3$ days, showing a unique growth layer. These characteristics are similar to those observed in the commercial cell lines MCF-7 and MDA-MB-231. Our cell lines were capable of proliferating, and their metabolic activity was maintained over 70 passages. We observed that, after 20 passages, MACL-1 and MGSO-3 cell lines presented stable proliferation rates comparable to that of MCF-7 and MDAMB-231 cell lines.

Alkaline phosphatase activity is used as a biomarker for cancer detection. This enzyme belongs to an isoenzyme family, whose increase is associated with malignancy (18). Alkaline phosphatase is overexpressed in some tumor tissues, in contrast to the original normal tissues that may express basal or undetectable levels (19). However, the role of alkaline phosphatase in cancer development has not been elucidated (20).

The increase in alkaline phosphatase production may be due to the activation of its gene in cells that do not normally express the enzyme or to the amplification of gene expression in cells that produce it at a basal level. Another possibility is that the proliferation of cells producing alkaline phosphatase would account for the increase in total production of this enzyme. Alkaline phosphatase activity of MACL-1 and MGSO-3 cell lines was increased compared to normal fibroblasts. Our data are in agreement with Van de Voorde et al (21), who observed the presence of alkaline phosphatase in breast cancer tumor extracts.

We next identified antigens shared by our cells, MACL-1 and MGSO-3, and the commercial cell lines, MCF-7 and MDA-MB-231. Accordingly, we produced rabbit anti-sera against MCF-7 and MDA-MB-231 whole cells. The sera were used in Western blot assays to detect antigens present in the four cell lines studied. We identified at least four antigens with different molecular weights in the extracts of the cell lines. The same antigens were not detected in the extracts of other non-breast cancer, control cell lines, such as PBMC, HEK, and HeLa, demonstrating that these four antigens are prevalent in breast cancer cells. 


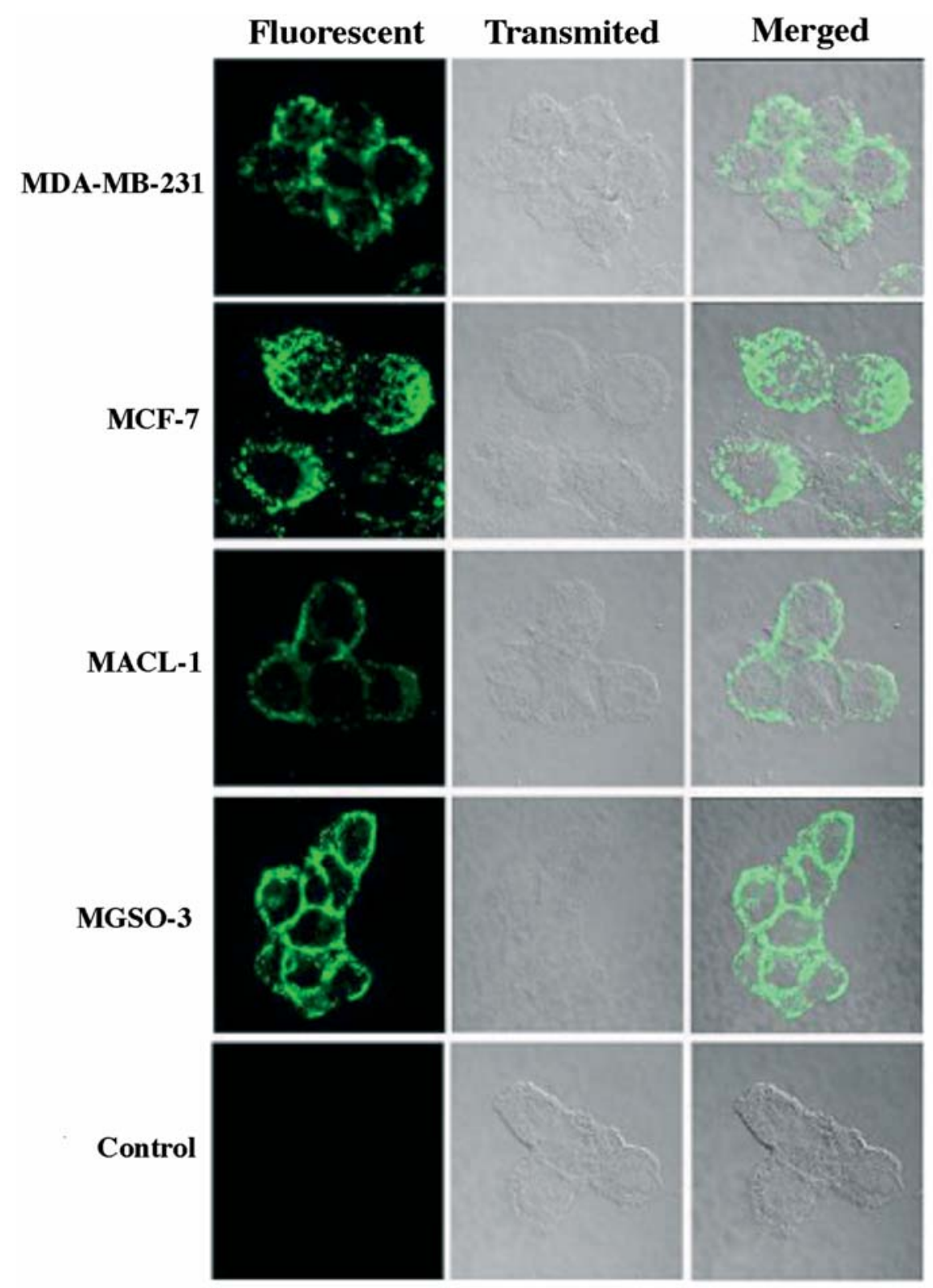

Figure 5. Evidence of surface antigens in primary breast cancer cell lines and commercial cell lines by immunofluorescence. Cells at $1 \times 10^{5}$ densities were seeded in chamber slides, and after $24 \mathrm{~h}$, were analyzed by specific fluorescent probes, after incubation with anti-MDA-MB-231 purified antibody. Left panel shows fluorescent image. Central panel shows transmission image. Right panel shows merged image. Data represent four different experiments.

Amino acid sequencing determined that the affinitypurified antigen of $37 \mathrm{kDa}$ from MCF-7 and MDA-MB-231 cells presented $100 \%$ homology with human glyceraldehyde-3phosphate dehydrogenase (GAPDH). The glycolytic enzyme GAPDH catalyzes the conversion of glyceraldehyde-3phosphate to 1,3-diphosphoglycerate (22). The activity of this enzyme is regulated by several glycolytic metabolites and by the association of the enzyme with cell membranes (23). This housekeeping gene is used as a paradigm, not only for analysis of protein structure and function, but also for model studies on gene structure and expression. Recent evidence indicates that GAPDH has new, intriguing roles in fundamental mammalian cell processes (24).

Tumor cells characteristically exhibit an increased rate of glycolysis $(25,26)$. There have been several studies showing an increase of GAPDH gene expression in a variety of human tumors and cell lines $(11,12,25,27-29)$. GAPDH is also thought to play a role in neoplastic transformation of hepatocytes (30), in tumor cell mobility, and metastasis in rat prostate adenocarcinoma tissue (31). Immunohistochemical analysis demonstrated that the subcellular localization of the human GAPDH protein displayed a defined pattern as a function of cell growth (32). In quiescent cells, GAPDH was detected only in the cytoplasm. In contrast, GAPDH was localized exclusively in the nuclear or perinuclear regions of proliferating cells. On the contrary, earlier studies identified GAPDH as a membrane bound protein in human cells and as a cell surface protein involved in fungal adhesion to extracellular matrix proteins (33-36).

We performed a co-localization experiment using antiGAPDH and anti- $\mathrm{Na}^{+} / \mathrm{K}^{+}$-ATPase (a plasma membrane protein) antibodies. In our work, we demonstrated the 
A

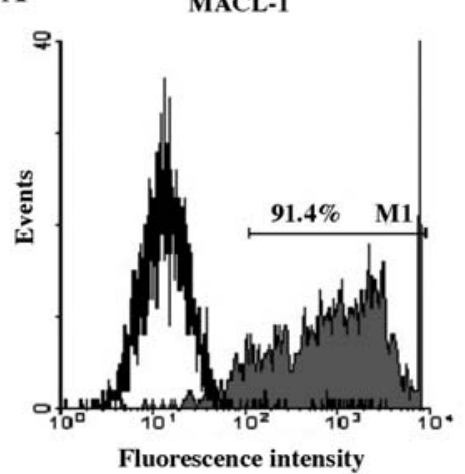

C

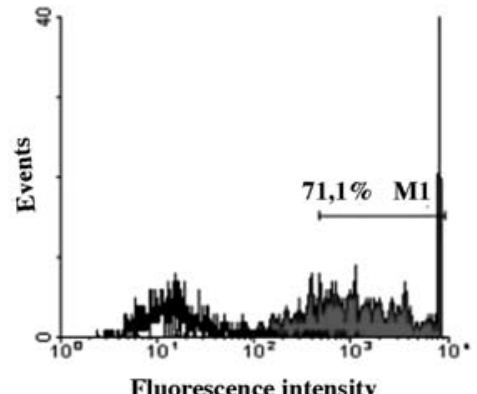

B

MGSO-3

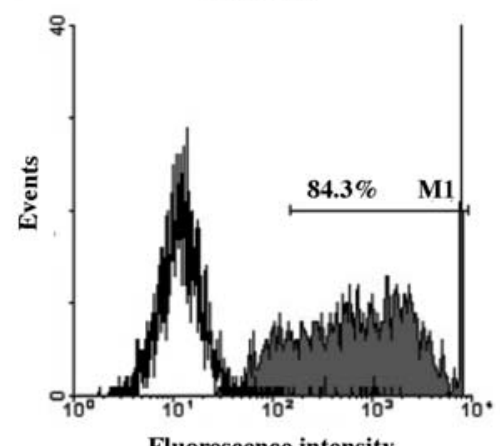

Fluorescence intensity

$\mathbf{D}$

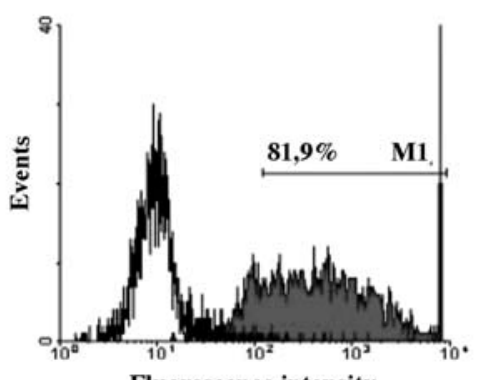

Figure 6. Evaluation of antigens commonly expressed by MACL-1, MGSO-3, MCF-7, and MDA-MB-231 breast cancer cell lines by flow cytometry using anti-MCF-7 antibodies (A-D). The fluorescence scale is on the X-axis and is positive when the gray peak of cells is $>10^{1}$. The empty black peak refers to unstained stem cells (negative control).

A

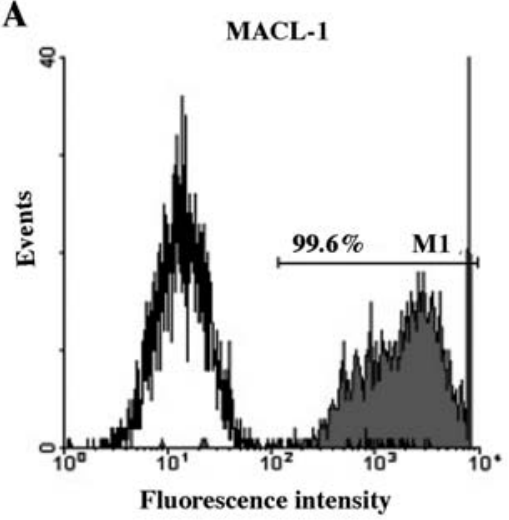

C

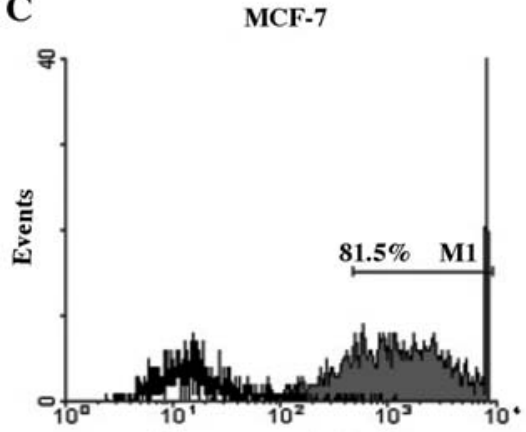

Fluorescence intensity
B

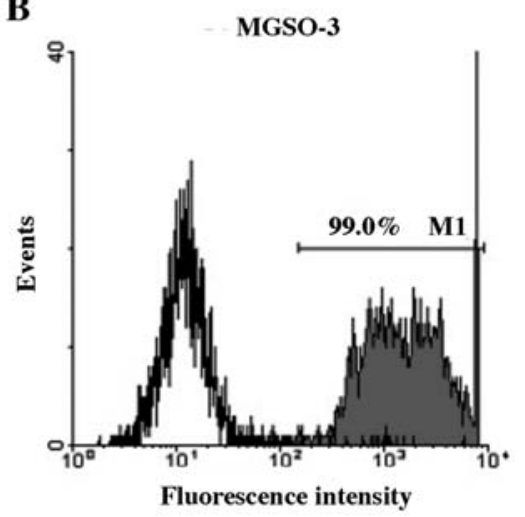

D

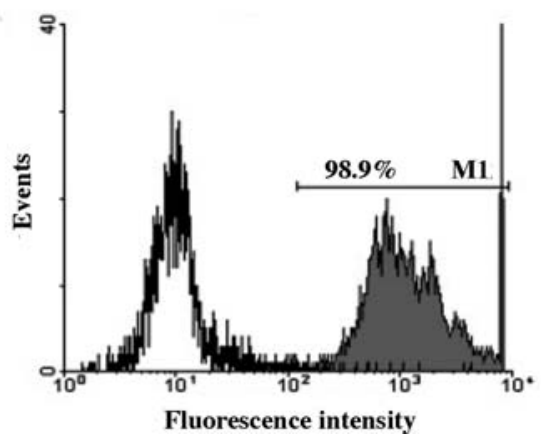

Figure 7. Evaluation of antigens commonly expressed by MACL-1, MGSO-3, MCF-7, and MDA-MB-231 breast cancer cell lines by flow cytometry using anti-MDA-MB-231 antibodies (A-D). The fluorescence scale is on the X-axis and is positive when the gray peak of cells is $>10^{1}$. The empty black peak refers to unstained stem cells (negative control). 


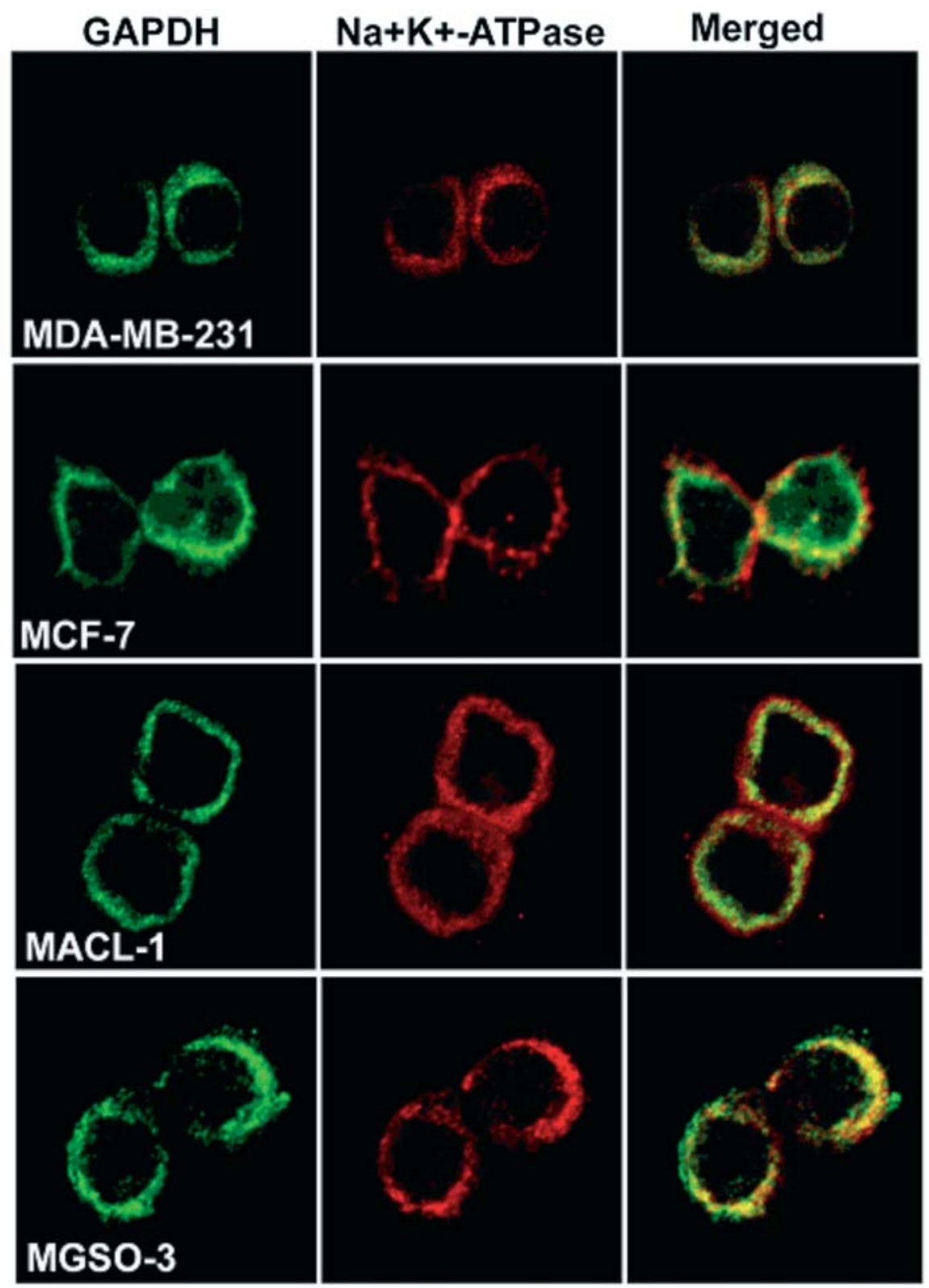

Figure 8. Evidence of GAPDH on the surface of primary breast cancer cell lines and commercial cell lines by immunofluorescence. Cells at $1 \times 10^{5}$ density were seeded in chamber slides, and after $24 \mathrm{~h}$, were analyzed by specific fluorescent probes, after incubation with anti-GAPDH and anti-Na ${ }^{+} / \mathrm{K}^{+} \mathrm{ATPase}$ monoclonal antibodies. Left and central panels show fluorescent images. Right panel shows merged image. Data represent four different experiments.

presence of GAPDH on the surface of MACL-1, MGSO-3, MCF-7, and MDA-MB-231 breast cancer cell lines. Our findings provide a new perspective on the role of GAPDH in tumor cells, including the mechanisms of exportation of this enzyme to the cellular membrane. Moreover, the differential expression of the GAPDH on the membrane could be used as a therapeutic target against breast cancer. For this purpose, new experiments need to be performed to verify the presence of GAPDH on the surface of other tumor cell lines, as well as its absence on the surface of normal tissue cell lines. In conclusion, our study showed the presence of GAPDH in the plasma membrane of four different breast cancer cell lines. This enzyme may represent a candidate for potential targets for future therapeutic strategies for breast cancer.

\section{Acknowledgements}

This study was supported by the Coordenação de Aperfeiçoamento de Pessoal de Nível Superior (CAPES/Brazil), Fundação de Amparo à Pesquisa do Estado de Minas Gerais (FAPEMIG/Brazil) and Conselho Nacional de Desenvolvimento Científico e Tecnológico (CNPq/Brazil).

\section{References}

1. Ferlay J, Bray F, Pisani P and Parkin DM: GLOBOCAN 2000: Cancer incidence, mortality and prevalence Worldwide. In: IARC Cancer Base. IARC (ed). Lyon, pp1-10, 2001

2. Mccallum HM and Lowther GW: Long-term culture of primary breast cancer in defined medium. Breast Cancer Res Treat 39: 247-258, 1996. 
3. Smith L, Welham KJ, Watson MB, Drew PJ, Lind MJ and Cawkwell L: The analysis of cisplatin resistance in breast cancer cells. Oncol Res 16: 497-506, 2007.

4. Goydos JS, Elder E, Whiteside TS, Finn OJ and Lotze MT: A Phase I trial of a synthetic mucin peptide vaccine. Induction of specific immune reactivity in patients with adenocarcinoma. J Surg Res 63: 298-304, 1996.

5. Fisk B, Blevins TL, Wharton JT and Ioannides CG: Identification of an immunodominant peptide of HER-2/neu protooncogene recognized by ovarian tumor-specific cytotoxic $\mathrm{T}$ lymphocyte lines. J Exp Med 181: 2109-2117, 1995.

6. Jiang XP, Yang DC, Elliot RL and Jonathan F: Vaccination with a mixed vaccine of autogenous and allogenic breast cancer cells and tumor associated antigens CA 15-3, CEA and CA 125 results in immune and clinical responses in breast cancer patients. Cancer Biother Radiopharm 15: 495-505, 2000.

7. Theobald M, Biggs J, Dittmer D, Levine AJ and Sherman LA: Targeting p53 as a general tumor antigen. Proc Natl Acad Sci USA 92: 11993-11997, 1995

8. Arai J, Yasukawa M, Ohminami H, Kakimoto M, Hasegawa A and Fujita S: Identification of human telomerase reverse transcriptase-derived peptides that induce HLA-A24-restricted antileukemia cytotoxic T lymphocytes. Blood 97: 2903-2907, 2001

9. Correa CR, Bertollo CM and Goes AM: Establishment and characterization of MACL-1 and MGSO-3 cell lines derived from human primary breast cancer. Oncol Res 17: 473-482, 2009

10. Sirover MA: Role of the glycolytic protein, glyceraldehyde-3phosphate dehydrogenase, in normal cell function and cell pathology. J Cell Biochem 66: 133-140, 1997.

11. Tokunaga K, Nakamura Y, Sakata K, et al: Enhanced expression of a glyceraldehyde-3-phosphate dehydrogenase gene in human lung cancers. Cancer Res 47: 5616-5619, 1987.

12. Schek N, Hall BL and Finn OJ: Increased glyceraldehyde-3phosphate dehydrogenase expression in human pancreatic adenocarcinoma. Cancer Res 48: 6354-6359, 1988

13. Kim JW, Kim JS, Han SM, Paik SY, Hur SY, Kim YW, Lee JM and Namkoong SE: Increased glyceraldehyde-3-phosphate dehydrogenase gene expression in human cervical cancers. Gynecol Oncol 71: 266-269, 1998.

14. Ouellet V, Ling TH, Normandin K, et al: Immunohistochemical profiling of benign, low malignant potential and low grade serous epithelial ovarian tumors. BMC Cancer 26: 346-354, 2008.

15. Bradford M: A rapid and sensitive method for the quantification of microgram quantities of protein utilizing the principles of protein-dye binding. Anal Biochem 72: 248-254, 1976.

16. Burdall SE, Hanby AM, Lansdown MRJ and Speirs V: Breast cancer cell lines: friend or foe? Breast Cancer Res 5: 89-95, 2003.

17. Valenti MT, Sartore S, Azzarello G, et al: Human fibroblasts from normal and malignant breast tissue grown in vitro show a distinct senescence profile and telomerase activity. Hist J 34: 403-410, 2002

18. Chang TC, Wang JK, Hung MW, Chiao CH, Tsai LC and Chang GG: Regulation of the expression of alkaline phosphatase in a human breast-cancer cell line. Biochem J 303: 199-205, 1994.

19. Harris H: The human alkaline phosphatases: what we know and what we don't know. Clin Chim Acta 186: 133-150, 1989.

20. Tsai LC, Hung MW, Chen YH, Su WC, Chang GG and Chang TC: Expression and regulation of alkaline phosphatase in human breast cancer MCF-7 cells. Eur J Biochem 267: 1330-1339, 2000.
21. Van de Voorde A, Groote G, Waele P, Broe ME, Pollet P, Boever J, Vandekerckhove D and Fiers W: Screening of sera and tumor extracts of cancer patients using monoclonal antibody directed against human placental alkaline phosphatase. Eur J Cancer Clin Oncol 21: 65-71, 1985.

22. Harris JI and Waters M: Glyceraldehyde-3-phosphate dehydrogenase. In: The Enzymes. Boyer P (ed). Academic Press, New York, pp1-49, 1976.

23. Tsai IH, Murphy SNP and Steck TL: Effect of red cell membrane binding on the catalytic activity of glyceraldehyde-3-phosphate dehydrogenase. J Biol Chem 257: 1438-1442, 1982.

24. Sirover M: Emerging new functions of the glycolytic protein, glyceraldehydes-3-phosphate dehydrogenase, in mammalian cells. Life Sci 58: 2271-2277, 1996.

25. Warburg O: On the origin of cancer cells. Science 123: 309-314, 1956.

26. Persons DA, Schek N, Hall BL and Finn OJ: Increased expression of glycolysis-associated genes in oncogene-transformed and growth-accelerated states. Mol Carcinog 2: 88-94, 1989.

27. Ohkubo M, Sawada K and Sakiyama E: Enhanced expression of a 37,000-dalton protein in human lung cancers. Jpn J Cancer Res 77: 546-553, 1986.

28. Perfetti V, Manenti G and Dragani TA: Expression of housekeeping genes in Hodgkin's disease lymph nodes. Leukemia 5: 1110-1112, 1991

29. Desprez PY, Poujol D and Saez S: Glyceraldehyde-3-phosphate dehydrogenase (GAPDH, E.C. 1.2.1.12.) gene expression in two malignant human mammary epithelial cell lines: BT-20 and MCF-7. Regulation of gene expression by 1,25-dihydroxyvitamin $\mathrm{D}_{3}\left(1,25-(\mathrm{OH})_{2} \mathrm{D}_{3}\right)$. Cancer Lett 64: 219-224, 1992.

30. Toshkov I, Hacker HJ, Roggendorf $M$ and Bannasch P. Phenotypic patterns of preneoplastic and neoplastic hepatic lesions in woodchucks infected with woodchuck hepatitis virus. J Cancer Res Clin Oncol 116: 581-590, 1990.

31. Epner DE, Partin AW, Schalken JA, Isaacs JT and Coffey DS: Association of glyceraldehydes-3-phosphate dehydrogenase expression with cell mobility and metastatic potencial of rat prostatic adenocarcinoma. Cancer Res 53: 1995-1997, 1993.

32. Cool BL and Sirover MA: Immunocytochemical localization of the base excision repair enzyme uracil DNA glycosylase in quiescent and proliferating normal human cells. Cancer Res 49: 3029-3036, 1989.

33. Tanner MJA and Gray WR: The isolation and functional identification of a protein from the human erythrocyte 'ghost' Biochem J 125: 1109-1117, 1971.

34. Wooster MS and Wrigglesworth JM: Adsorption of glyceraldehydes 3-phosphate dehydrogenase on condensed monolayers of phospholipids. Biochem J 153: 93-100, 1976.

35. Kant JA and Steck TL: Specificity in the association of glyceraldehyde 3-phosphate dehydrogenase with isolated human erythrocyte membranes. J Biol Chem 248: 8457-8464, 1973.

36. Barbosa MS, Bao SN, Andreotti PF, de Faria FP, Felipe MS, Feitosa LS, Mendes-Giannini MJ and Soares CM: Glyceraldehyde 3-phosphate dehydrogenase of Paracoccidioides brasiliensis is a cell surface protein involved in fungal adhesion to extracellular matrix proteins and interaction with cells. Infect Immunol 74: 382-389, 2006. 